\title{
CEREBELLAR HYPOPLASIA IN WERDNIG-HOFFMANN DISEASE
}

\author{
BY \\ R. M. NORMAN \\ From the Burden Neuropathological Laboratory, Frenchay Hospital, Bristol
}

(RECEIVED FOR PUBLICATION JULY 26, 1960)

It is well established that the neuropathological changes in the Werdnig-Hoffmann disease are not confined to the spinal cord and brain stem, and that sensory as well as motor nuclei may be involved. Gruner and Bargeton (1952) found evidence of neuronal degeneration in the thalamus in all their nine cases and Radermecker $(1951,1953)$ has reported occasional lesions in the striatum, globus pallidus, nucleus subthalamicus, cerebellar cortex and dentate nucleus. In contrast to this wealth of degenerative change, reports of malformations in association with Werdnig-Hoffmann disease have been conspicuous by their absence, except for doubling of the central canal of the spinal cord in one of Werdnig's (1891) cases, and a few reports of minor neuronal heterotopias (Brandt, 1950). There is, however, an account by Radermecker and Liessens (1954) of a family in which the same sibship contained proved cases of Werdnig-Hoffmann disease and also a child who suffered from a nonprogressive ataxia considered to be due to cerebellar hypoplasia.

The case to be described in this paper is remarkable not only for the presence of a prenatal cerebellar malformation but also for the widespread distribution of supra-segmental degenerative lesions. Evidence will be adduced to support the view that in Werdnig-Hoffmann disease, as in certain other infantile encephalopathies, malformation may be an early expression of the genetic abnormality responsible for the later manifestations of the disease.

\section{Case Report}

Clinical History. J.S., a boy, was the only child of healthy parents who were not blood relatives. The pregnancy had been uneventful. He was born by breech presentation and sustained a fracture of the right humerus with a right Erb's palsy. The birth weight was $43 \mathrm{lb}$. There was initial difficulty in establishing respiration and he was extremely limp and had to be tube fed. After the first three weeks he began to feed and the limpness became less noticeable. At about the age of 2 months a slight adductor spasm of the legs was observed and as time passed it was noted that he was not only failing to reach the normal milestones of development but that a progressive mental deterioration was taking place. Death occurred from bronchopneumonia at the age of 6 months.

\section{Examination of the Central Nervous System.}

MACrosCopic. The brain after fixation weighed $603 \mathrm{~g}$. of which the cerebellum and brain stem accounted for $21 \mathrm{~g}$. The convolutional pattern of the cerebral hemispheres was normal. On coronal section it was seen that the corpus callosum was thin, and its splenium unduly small, that the lateral ventricles were moderately enlarged, and that the thalami appeared to be unusually small. The cerebellum was small and flat and its posterior margin only reached a point $4 \mathrm{~cm}$. from the occipital poles. This reduction in size affected the inferior semilunar lobules, the tonsils and biventral lobules, the gyri of which were unusually broad and separated from each other by very shallow sulci. This foetal type of configuration was symmetrical (Fig. 1). The inferior vermis did not share in this change, nor did the flocculi. The dorsal surface of the cerebellum was normally convoluted.

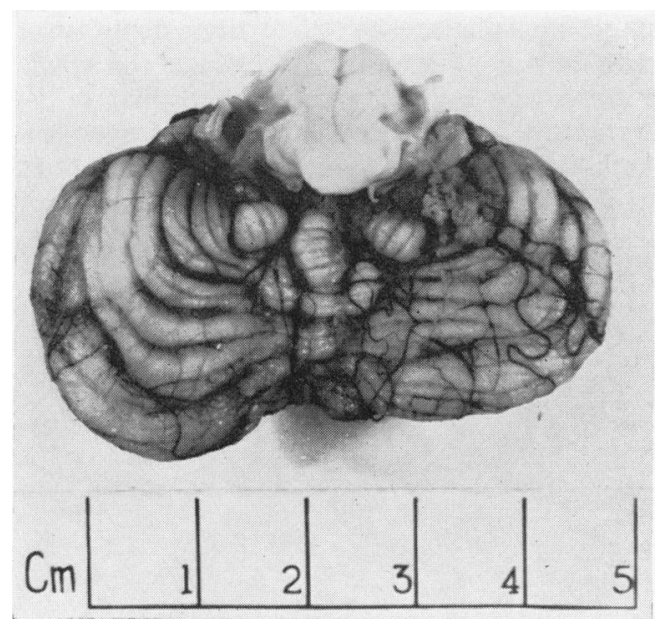

FIG. 1.-Cerebellum; inferior surface showing primitive simplification of gyri. 
Microscopic. Whole-brain coronal celloidin sections were prepared serially from the anterior part of the corpus striatum to the pulvinar, every 80th section being stained for nerve cells and the adjoining section for myelin. The occipital lobes were examined separately. The cerebellum and brain stem were also serially sectioned in a plane at right angles to the axis of the brain stem, every 40th section being examined. Representative sections were stained for fibrous neuroglia by the Holzer method and for axis cylinders by the Gros-Bielschowsky stain. The spinal cord was examined both in celloidin and frozen sections.

SpINAl Cord. There was a marked reduction in the number of anterior horn cells in the cervical and lumbar regions. Several of the remaining nerve cells showed swelling and chromatolysis, the nucleus often lying flattened at the margin of the cell (Fig. 2). In the grey matter there was a diffuse overgrowth of fibrillary neuroglia, fanning out into the anterior and lateral columns in the cervical and lumbar segments and also involving the posterior columns in the thoracic region. This gliosis did not reach the periphery of the cord (Fig. 3). Myelination of the tracts was within normal limits except in the thoracic and lumbar regions where there was a clear-cut pallor in the crossed pyramidal tracts (Fig. 4). In the lumbar cord the well myelinated posterior columns showed conspicuous fibrillary gliosis. The anterior nerve roots were atrophic in the cervical and lumbar enlargements.

Brain STEM. Examination of the serial sections provided evidence of widespread neuronal degeneration, though myelination was normal for the patient's age. Swollen chromatolytic nerve cells with eccentric nuclei were found in the following cranial nerve motor nuclei: XII, VII, VI, V, IV and III (Fig. 6b). The hypoglossal nucleus at some levels also showed a reduction in the number of nerve cells. The most caudal part of the inferior olives contained few nerve cells and the capsule

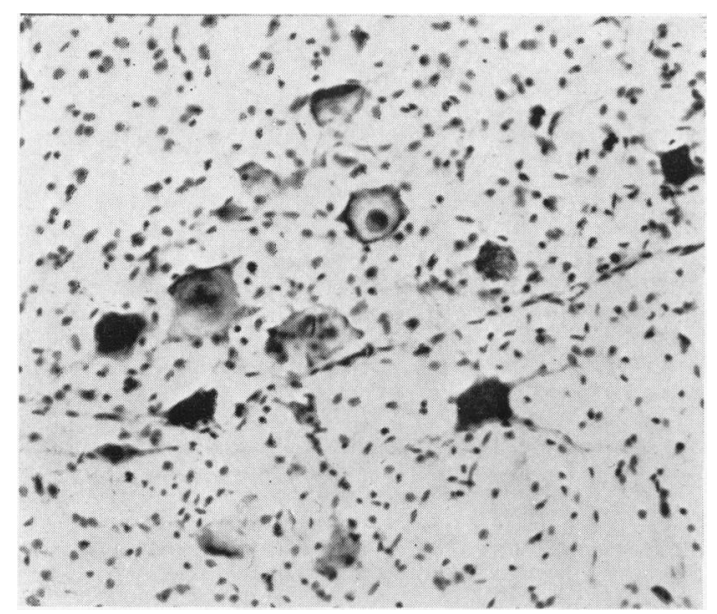

FIG. 2.-Spinal cord; lumbar enlargement; the anterior horn cells show various stages of degeneration. (Carbol azure $\times 170$.)

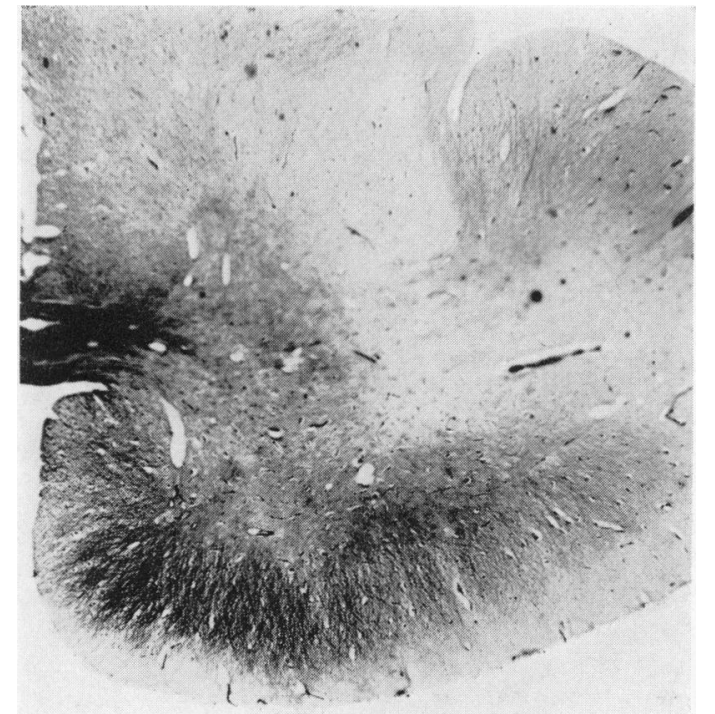

Fig. 3.-Cervical cord; fibrous gliosis in the anterior columns. (Holzer $\times$ 18.)

and hilum showed heavy fibrillary gliosis. The dorsal accessory olive was also partially degenerated. In places the oral parts of the inferior olives were poorly convoluted, the dorsal band being formed by a widely spaced double line of nerve cells. There was severe degeneration and gliosis of the medial and lateral vestibular nuclei in which neuronophagia was in progress (Fig. 5). In the oral part of the pons the nuclei pontis showed a marked reduction in the nerve cell population of the dorso-lateral cell groups. There was marked fibrous gliosis in the transverse fibres of the pons, but no demonstrable reduction in the numbers of axons. A large nest of primitive nerve cells was attached to the posterior medullary velum and bulged conspicuously into the fourth ventricle (Fig. 10).

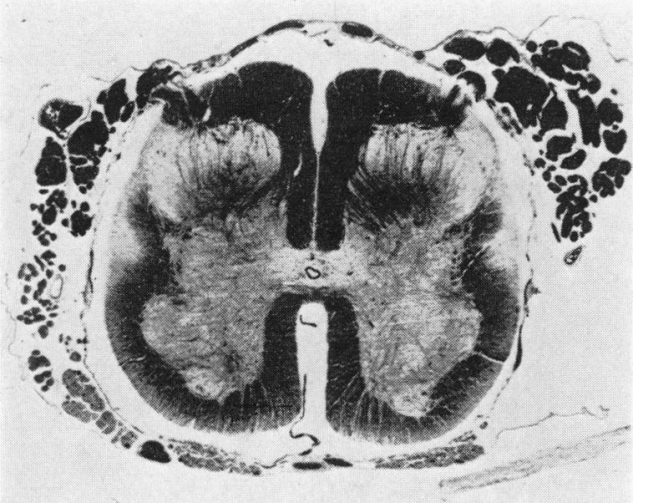

Fig. 4.-Fifth lumbar segment; atrophy of the anterior roots. The lateral pyramidal tracts are demyelinated. (Heidenhain $\times$ 8.) 


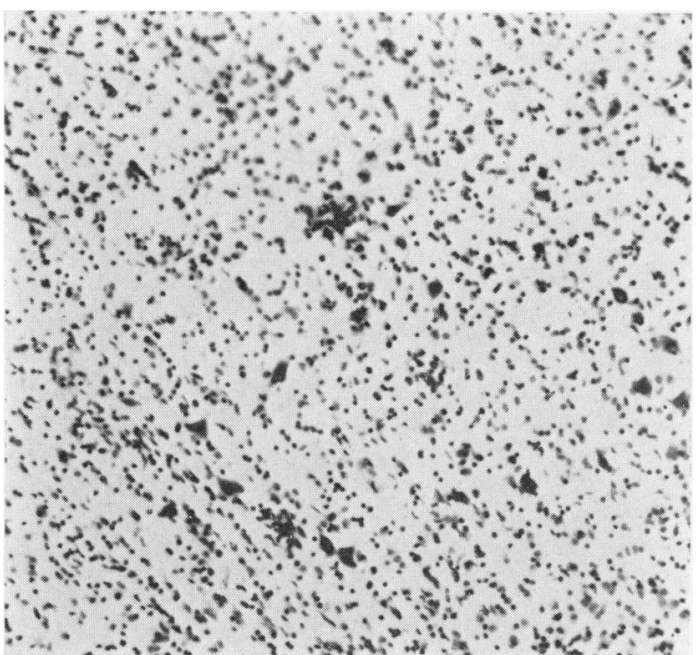

FIG. 5 .

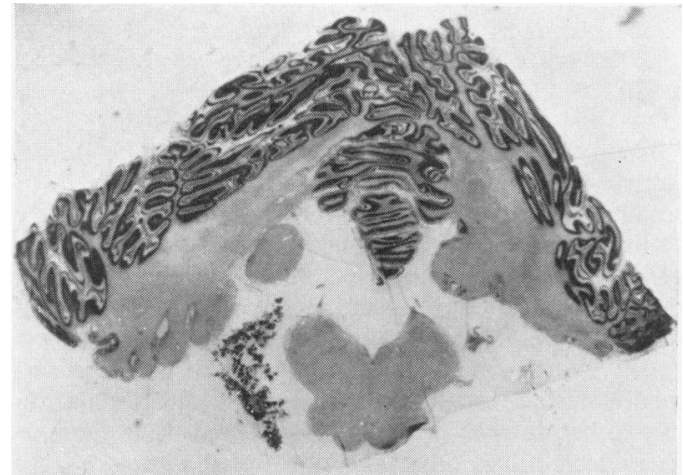

FIG. 7.

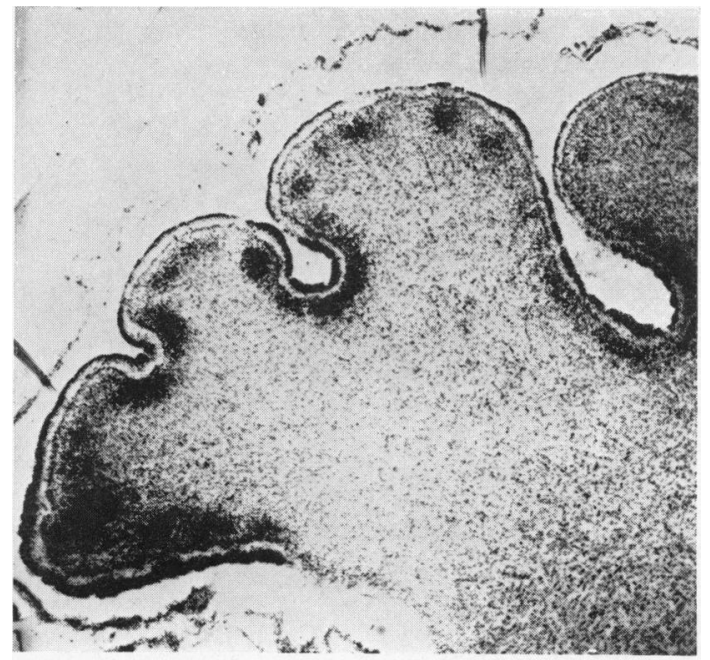

FIG. 8.

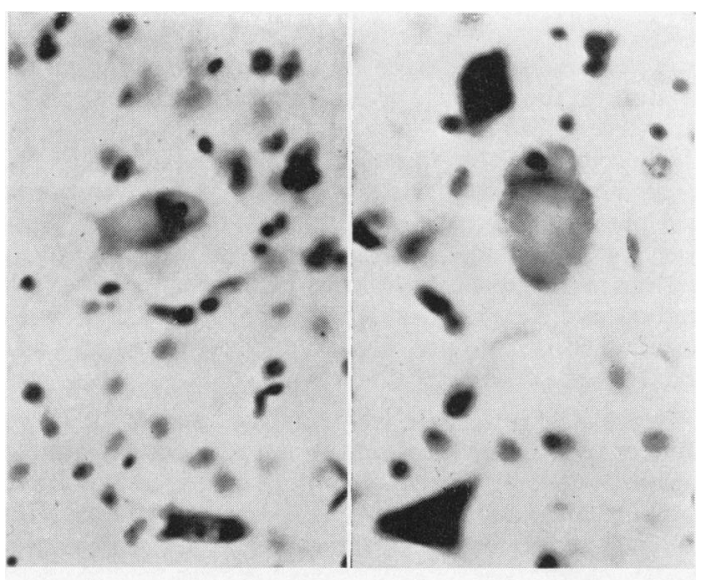

FIG. 6.

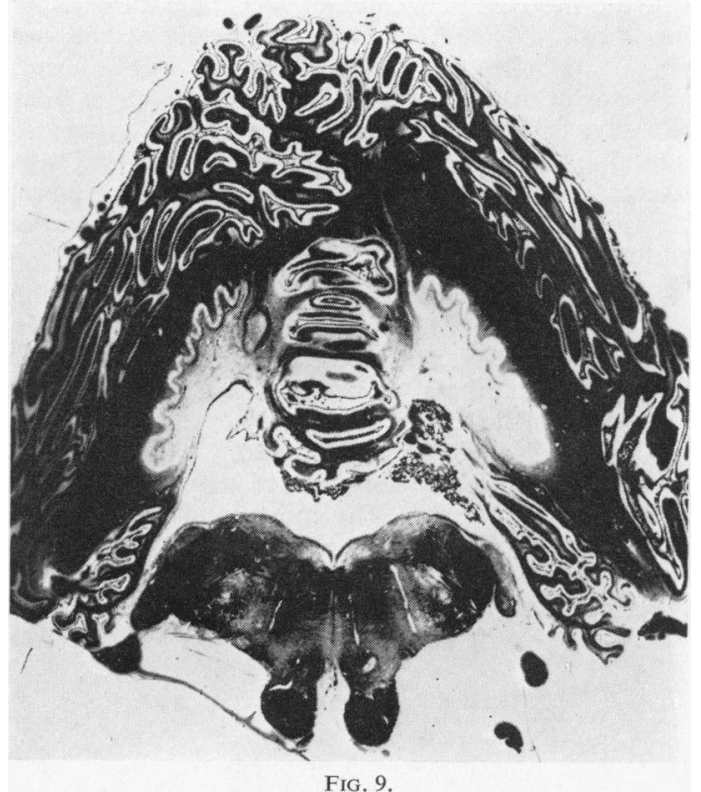

FIG. 5.-Lateral vestibular nucleus showing gliosis, loss of many nerve cells and two figures of neuronophagia. (Carbol azure $\times 120$.)

FIG. 6.-Typical chromatolytic nerve cell of globus pallidus (a) and of trochlear nucleus (b). (Carbol azure (a) $\times 375$; (b) $\times 470$.)

Fig. 7.-Atrophy of the gyri of the tonsils and inferior semilunar lobules. The vermis and dorsal parts of the lateral lobes are hypoplastic. (Carbol azure $\times 1 \cdot 5$.)

FIG. 8.-Atrophic gyri showing patchy remnants of the internal granular layer. (Carbol azure $\times 17$.)

Fig. 9.-Demyelination of the dentate nuclei and their hila. (Heidenhain $\times 2 \cdot 7$.) 


\section{CEREBELLAR HYPOPLASIA IN WERDNIG-HOFFMANN DISEASE}

Cerebellum. Microscopic examination of the poorly developed gyri of the inferior surface showed that most of these formations were devoid of nerve cells and axis cylinders (Fig. 7). In areas adjoining the more normal cortex the internal granular layer was represented by small groups of cells usually in the deeper parts of the walls of the shallow sulci (Fig. 8). In such areas a few Purkinje cells were seen, some of which were binucleate, and a thin external granular layer, less dense than elsewhere in the cerebellum, was also present. These atrophic gyri were filled by a thin, uniform feltwork of glial fibres except in the molecular layer where the fibres of the Bergmann astrocytes formed a dense brushwork.

The folia of the vermis and dorsal parts of the lateral lobes were normally constituted and there was no sign of neuronal degeneration. Myelination was unimpaired though a mild fibrous gliosis was present throughout the central white matter. Both dentate nuclei showed a severe and diffuse loss of nerve cells accompanied by demyelination and heavy gliosis of their hila (Figs. 9 and 10). The caudal part of both nuclei had not developed their normal convoluted pattern and appeared to have been formed by rounded masses of nerve cells. The nucleus fastigii was intact.

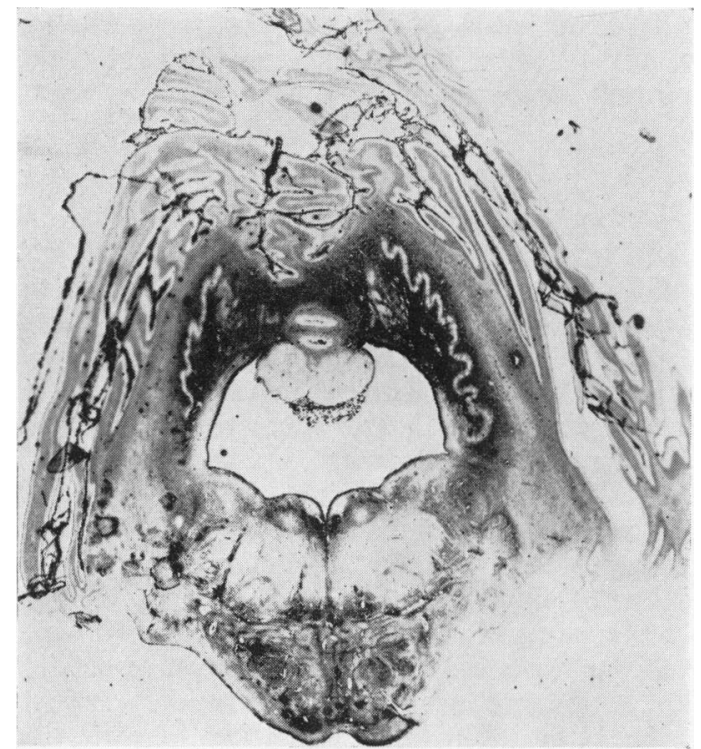

Fig. 10.-Fibrous gliosis of the dentate nuclei and deeper white matter of the cerebellar hemispheres. The pons shows gliosis of the nuclei in the floor of the fourth ventricle and in the pes pontis. The outline of the large nest of primitive cells is seen in the roof of the ventricle. (Holzer $\times 2 \cdot 7$.)

BASAL GANGlia. Widespread and remarkably symmetrical loss of nerve cells was found in the thalamus, the severest changes being present in the postero-lateral group of nuclei and in the central part of the dorsomedial nucleus (Fig. 11). Many of the surviving nerve

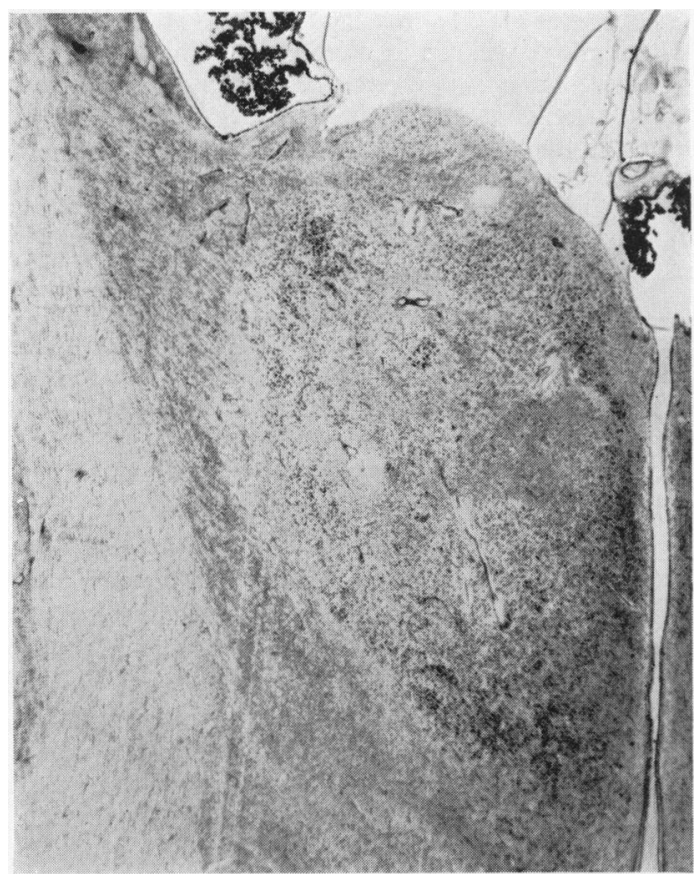

FIG. 11.-Left thalamus showing extensive loss of nerve cells in the anterior, medial and lateral nuclei. (Carbol azure $\times$ 8.)

cells showed complete chromatolysis with lateral displacement of the nucleus, and microglial activity was often conspicuous in the neighbourhood of such cells. The nuclei of the midline, and the centro-median and parafascicular nuclei were preserved. The external geniculate body also contained scattered chromatolytic cells. No pathological changes were present in the caudate nucleus or putamen of either side. The globus

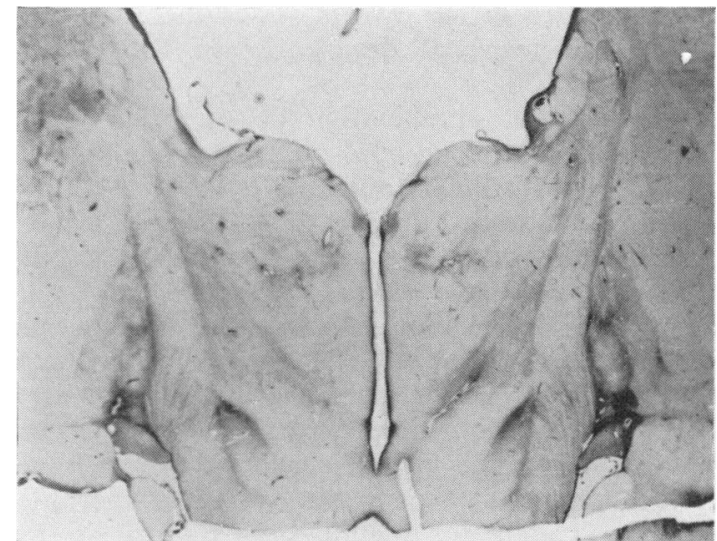

FIG. 12.-Fibrous gliosis marks each globus pallidus and nucleus subthalamicus, Slight gliosis is also seen in the thalami. (Holzer $\times 2 \cdot 7$.) 
pallidus was feebly myelinated and showed diffuse fibrous gliosis which was most marked in the medullary laminae. There was a patchy loss of nerve cells, many of the remaining cells staining feebly and a few being fully chromatolytic. The corpora Luysii showed a symmetrical atrophy of the dorso-lateral half, there being a severe loss of nerve cells and marked fibrous gliosis. Here also there were occasional chromatolytic cells and patchy microglial activity.

Cerebral Cortex. A wide sampling revealed no pathological changes. The white matter of the centrum ovale, gyral cores and long tracts coloured less intensely with the myelin stain than is usual at 6 months, but no gliosis was present.

\section{Discussion}

The progressive neurological deterioration noted in this child had struck a discordant note in a history otherwise suggestive of cerebral birth trauma, and the neuropathological examination revealed the classical features of Werdnig-Hoffmann disease in the spinal cord and brain stem, while showing no evidence of vascular or anoxic lesions. The chromatolytic swelling of the anterior horn cells and of the neurones in the cranial nerve nuclei closely resembled that of axonal reaction and is highly characteristic of Werdnig-Hoffmann disease. On the other hand, partial degeneration of the pyramidal tracts has been reported only in a minority of cases (Radermecker, 1951). In the present instance this lesion may well have been responsible for the adductor spasticity observed at one stage of the illness.

The loss of nerve cells in the thalami and pallidoLuysial system was exceptionally severe, but the presence of microglial activity and the typical chromatolysis in some of the remaining nerve cells were again features of Werdnig-Hoffmann disease that have been described in several other cases, including two of my own in which there was also widespread neuronal devastation in the thalami (Norman, 1958).

The peculiar combination of cerebellar hypoplasia and convolutional atrophy is a unique finding in Werdnig-Hoffmann disease. Although it is well established that the disease may be present at birth (Beevor, 1902), up to now there has been no evidence that the degenerative process may start so early in foetal life as to interfere with normal structural development. Yet in the present case the primitive form of the gyri in the ventral parts of the lateral lobes taken in conjunction with the marked gliosis and lack of cortical neurones leaves little doubt as to the prenatal onset of the abiotrophy. The minor malformations noted in the partially degenerate dentate nuclei and inferior olives also point to the same conclusion.
Cerebellar hypoplasia has been found associated with progressive neuronal degeneration in the brain stem and basal ganglia in other infantile encephalopathies (Gross and Kaltenbäck, 1959; Norman and Urich, 1958) and there is reason to believe that the two processes are not fortuitously linked. The appearance of cerebellar hypoplasia in a case of Werdnig-Hoffmann disease thus strengthens the theory that both the malformation and abiotrophy may be the expression of a single genetic abnormality. There is some clinical evidence to support this view. Radermecker and Liessens (1954) reported a remarkable pedigree of two interrelated Flemish families in which four infants suffered from Werdnig-Hoffmann disease. Another sibling presented signs of cerebellar ataxia at the end of the second year of life. In this patient the muscles were poorly developed but their electrical reactions were normal. By the age of 5 years this child had shown an improvement both in the ataxia and in his muscular development and there was still no sign of motor neurone disease. The diagnosis of cerebellar hypoplasia was made. The authors hesitated to classify this non-progressive cerebellar syndrome as a forme fruste of Werdnig-Hoffmann disease, but in the light of the present case this explanation may well be correct.

\section{Summary}

Neuropathological examination of a 6-month-old infant revealed the usual features of WerdnigHoffmann disease in the spinal cord and brain stem. There was widespread degeneration of nerve cells in the thalami, and symmetrical pallido-Luysial atrophy. The cerebellum was hypoplastic and in the ventral parts of the lateral lobes the convolutions were stunted in development and showed atrophic changes. Severe degeneration had taken place in both dentate nuclei and was accompanied by dense fibrillary gliosis and an almost complete loss of myelinated fibres in the hila. Reference is made to other forms of infantile encephalopathy in which cerebellar hypoplasia has been found in association with progressive neuronal degeneration elsewhere in the brain. The findings in the present case support the theory that, in certain instances, prenatal malformation and abiotrophy are expressions of the same genetic abnormality.

I am greatly indebted to Dr. W. J. Matheson for the use of his clinical notes and to Dr. E. M. Stirk who performed the autopsy and made this brain available for examination.

This work was carried out with the help of the Nuffield Foundation. 


\section{REFERENCES}

Beevor, C. E. (1902). A case of congenital spinal muscular atrophy (family type), and a case of haemorrhage into the spinal cord at birth giving similar symptoms. Brain, 25, 85 .

Brandt, S. (1950). Werdnig-Hoffmann's Infantile Progressive Muscular Atrophy, p. 82. Opera ex domo biological hereditariae humanae universitaris Hafniensis, No. 22. Munksgaard, Copenhagen.

Gross, H. and Kaltenbäck, E. (1959). Über eine kombinierte Progressive pontocerebellare Systematrophie bei einem Kleinkind. Dtsch. $Z$. Nervenheilk., 179, 388.

Gruner, J.-E. and Bargeton, E. (1952). Lésions thalamiques dans la myatonie du nourrisson. Rev. neurol., 86, 236.

Norman, R. M. (1958). Neuropathology, ed. J. G. Greenfield, p. 382. Arnold, London.
- and Urich, H. (1958). Cerebellar hypoplasia associated with systemic degeneration in early life. J. Neurol. Neurosurg. Psychiat., 21, 159.

Radermecker, J. (1951). L'amyotrophie spinale de l'enfance (Werdnig-Hoffmann) comme hérédo-dégénérescence. Rev. neurol., 84, 14.

- (1953). Sur les lésions supra-spino-bulbaires dans l'amyotrophie de Werdnig-Hoffmann. Ibid., 89, 368.

- and Liessens, P. (1954). Une hypogénésie cérébelleuse dans une souche d'amyotrophie de Werdnig-Hoffmann. Acta neurol. belg., 54, 128.

Werdnig, G. (1891). Zwei frühinfantile hereditäre Fälle von progressiver Muskelatrophie unter dem Bilde der Dystrophie, aber auf neurotischer Grundlage. Arch. Psychiat. Nervenkr., Berl., 22, 437. 